\title{
A GESTÃO DA SEGURANÇA PÚBLICA NOS DELITOS DE TRÂNSITO ENVOLVENDO ABUSO DE DROGAS
}

\section{ARTIGO ORIGINAL}

JÚNIOR, José Aglair Barbosa de Freitas ${ }^{1}$

SILVA, Ana Paula Lopes da ${ }^{2}$

DENDASCK, Carla Viana ${ }^{3}$

MOREIRA, Elisângela Claudia de Medeiros ${ }^{4}$

OLIVEIRA, Euzébio de ${ }^{5}$

PINHEIRO, Maria da Conceição Nascimento ${ }^{6}$

JÚNIOR, José Aglair Barbosa de Freitas. Et al. A gestão da Segurança Pública nos delitos de trânsito envolvendo abuso de drogas. Revista Científica Multidisciplinar

1 Mestre em Gestão Pública pela Universidade de Lusófona de Humanidades Tecnologia - ULHT - Portugal.

2 Doutorado em História e Filosofia das Ciências. Docente da Universidade de Lusófona de Humanidades Tecnologia - ULHT - Portugal.

${ }^{3}$ Teóloga. Doutora em Psicanálise Clínica. Pesquisadora do Centro de Pesquisa e Estudos Avançados, São Paulo, SP.

${ }^{4}$ Mestre em Teoria e Pesquisa do Comportamento. Docente da Universidade do Estado do Pará - UEPA. Doutoranda em Medicina/Doenças Tropicais na Universidade Federal do Pará - NMT/UFPA.

${ }^{5}$ Doutor em Medicina/Doenças Tropicais. Docente e Pesquisador na Universidade Federal do Pará - UFPA. Pesquisador Colaborador do Núcleo de Medicina Tropical NMT/UFPA.

${ }^{6}$ Doutora em Neurociências e Biologia Celular. Docente e Pesquisadora do Núcleo de Medicina Tropical - NMT/UFPA. 
Núcleo do Conhecimento. Ano 04, Ed. 12, Vol. 07, pp. 05-16. Dezembro de 2019. ISSN: 2448-0959, Link de acesso: https://www.nucleodoconhecimento.com.br/lei/gestao-da-seguranca-publica

\section{RESUMO}

O abuso de drogas em acidentes de trânsito constitui um desafio para a gestão da segurança pública no mundo contemporâneo. Com o uso crescente de drogas ilícitas e o aumento da frota de veículos no Brasil, preocupa a possibilidade das normas e legislação atuais relacionadas às drogas no trânsito não atenderem às demandas específicas, exigindo desta forma, uma avaliação das ações na gestão na segurança pública. Este trabalho propõe verificar se os procedimentos realizados nas perícias em crimes de trânsito envolvendo abuso de drogas ilícitas são adequados. Trata-se de um estudo de caso que incluiu observação in loco e análise documental incluindo documentos oficiais que dão suporte às perícias técnico-científicas realizadas em uma unidade regional de perícia científica no Estado do Pará. Para a apresentação e avaliação dos dados utilizou-se a análise de conteúdo que permitiu concluir que a segurança pública nos crimes de trânsito envolvendo abuso de drogas ilícitas conta com recursos humanos experientes e qualificados, porém a infraestrutura física e a legislação pertinente e disponível são limitadas para o bom desempenho das perícias em relação ao esclarecimento de drogas ilícitas envolvidas em acidentes de trânsito.

Palavras Chave: Drogas ilícitas, acidentes de trânsito, segurança pública, gestão.

\section{INTRODUÇÃO}

Alguns países têm dispensado muita atenção ao envolvimento de álcool e outras drogas nos crimes de trânsito envolvendo abuso de drogas, visando orientar a adoção de medidas que objetivam a redução da incidência desses eventos (MURA et al., 2006; COSTA et al., 2012; VEISTEN et al., 2013; SIMONSEN; LINNET; RASMUNSEN, 2018). Há décadas, muitos países adotam como estratégias legislações que proíbem o uso do álcool por condutores de veículos automotores, estabelecendo limites de alcoolemia permitida, inclusive usando etilômetros no local 
de abordagem ao motorista. Entretanto, a criação de novas leis e métodos capazes de detectar a presença de outras drogas, além do álcool em motoristas é bastante recente em alguns países (VEISTEN et al., 2013).

Países como Alemanha, Portugal, França e outros da União Europeia definiram como ações prioritárias para a redução de número de mortes no trânsito, a atuação continuada contra o problema do motorista que dirige sobre efeito de álcool, bem como a busca por soluções quanto ao uso de outras drogas que causem prejuízo na capacidade de operar veículos automotores (WHO, 2016). Admite-se que qualquer quantidade de substância psicoativa é capaz de provocar alterações cognitivas e motoras que vão influenciar no desempenho negativo na condução de veículos automotores, seja através de seus efeitos agudos, seja por meio de seus resíduos ou de abstinência (HIGSON; WINTER, 2003; BUSARDÒ et al., 2018). Além disso, o uso de duas ou mais substâncias psicoativas em motoristas envolvidos em acidentes automobilísticos tem sido demonstrado (KARJALAINEN et al., 2010).

No Brasil, os acidentes de trânsito têm crescido com registro de casos fatais nas últimas décadas. Dados recentes do Sistema Único de Saúde registraram em 2014 cerca de 40 mil óbitos decorrentes de acidentes de trânsito, representando uma das principais causas de morte no país (DATASUS, 2014). Os acidentes nas rodovias federais respondem por cerca de $20 \%$ dessas mortes (8.227) com cerca de 30 mil feridos graves por ano, gerando fortes impactos no orçamento público e na renda das famílias atingidas (IPEA, 2015).

Algumas medidas foram colocadas em prática no país, na tentativa de diminuir esses acidentes, embora sem sucesso. Novas leis, controle de tráfego local, melhoria na segurança dos veículos e aumento no monitoramento eletrônico de tráfego falharam em tentar reduzir mortes e lesões graves (BACCHIERE; BARROS, 2011).

A maioria dos estudos sobre acidentes de trânsito inclui como causa o uso do álcool na direção de veículos (CAMPOS et al., 2008; MALTA et al., 2015). Enquanto, o registro de drogas ilícitas com ou sem associação com o álcool encontra-se bem menos publicado. Um levantamento de causas de acidentes de trânsito realizado pelo 
Departamento de Trânsito (DETRAN) no Estado do Pará nos anos de 2007, 2008 e 2009 mostrou apenas a embriaguez alcoólica como uma das causas de acidentes de trânsito, não havendo referência de drogas ilícitas no envolvimento com esses acidentes (DETRAN/SISP, 2009) e em outro estudo as drogas psicoativas foram relacionadas com mortes violentas na região metropolitana de Belém (NUNES, 2012).

No contexto das provas do direito admitidas em caso de acidentes de trânsito, destacam-se as provas testemunhais e as provas materiais, dentre as quais, as provas materiais resultantes da perícia representam as provas de grande importância. Peritos consideram que a prova de embriaguez alcoólica e de outras drogas ilícitas se fundamentam no tripé constituído pela prova testemunhal, o exame clínico e o exame toxicológico (SOUZA; MUNHOZ, 2002).

A perícia médico-legal é de fundamental importância para aplicação da lei. A realização do exame clínico e os testes toxicológicos deveriam fazer parte das perícias em acidente de trânsito com vista ao aperfeiçoamento e fortalecimento da prova material. Entretanto, isso não é a regra, no país. Conforme sugeriram Alvarez, Fierro e Del Rio (2007), os dados toxicológicos obtidos podem ser de grande utilidade para o desenvolvimento de políticas de prevenção direcionadas para aqueles que dirigem sob efeito de drogas.

Apesar de, o Código de Trânsito Brasileiro (CTB) estabelecer em seu parágrafo 2.. que a prova de embriagues poderá ser obtida mediante teste de alcoolemia, exame clínico, perícia, vídeo, prova testemunhal ou outros meios de prova, há nítida omissão da conduta em relação às outras drogas psicoativas (CTB, 1997).

Como dever do estado em adotar medidas que ofereçam segurança a todos os brasileiros, O CTB estabelece no art. $1^{\circ}$, $\S 2^{\circ}$ a responsabilidade deste no âmbito das devidas competências (estaduais, municipais) em assumir pelos danos causados aos cidadãos em virtude de ação, omissão, ou erro na execução, e manutenção de programas, projetos e serviços que garantam o exercício do direito do trânsito seguro (CTB, 1997). Nesse contexto, a segurança pública deve assumir a prevenção e o controle das ações no que diz respeito aos delitos causados pelos acidentes de 
trânsito, incluindo aqueles envolvendo abuso de drogas, dando suporte às instâncias jurídicas, se for o caso.

A segurança pública em crimes de trânsito, no Brasil, particularmente, no Estado do Pará, não estabeleceu uma padronização para as ações periciais. Não há evidências que nas perícias de trânsito, envolvendo abuso de drogas o exame clínico, o exame toxicológico para drogas ilícitas seja realizado regularmente. Em geral, a única prova solicitada é a de alcoolemia quando há suspeita de embriaguez alcoólica. Em consequência dessa conduta, a apreciação de caso concreto pode entrar em conflito com a prova material (por ausência ou por inadequação do exame realizado) e o depoimento de testemunha.

Com o uso abusivo de drogas ilícitas no país e o aumento da frota de veículos automotores previsto pelo Instituto Pesquisa Econômico Aplicado (IPEA, 2014), podese esperar uma tendência crescente de acidentes de trânsito trazendo sérias implicações para o sistema de saúde, previdenciário e para a segurança pública.

A regulamentação de utilização regular de testes toxicológicos para ser aplicado em autores e vítimas de acidentes de trânsito deve ser da competência da gestão pública estadual ou municipal com vista à contribuição para o esclarecimento das causas e para subsidiar o inquérito policial na definição de penas, multas e suspensões aos verdadeiros culpados. A ausência de uma padronização de testes toxicológicos para o álcool e drogas ilícitas contribui para a fragilidade das periciais técnicas, as quais podem influenciar negativamente nos inquéritos policiais.

Os elevados registros de casos e mortes por acidentes de trânsito mostram tendência com crescimento da frota de veículos no país (LEYTON et al., 2019; SCHERER et al., 2019). Na maioria dos acidentes o álcool tem sido implicado como causa, entretanto, pouco é conhecido sobre o envolvimento de outras drogas psicoativas, isoladas ou associadas ao álcool no envolvimento nos crimes de trânsito ocorrido no Brasil. O uso descontrolado de drogas no país exige que as leis aplicadas nos crimes de trânsito sejam adequadas à situação atual. $\mathrm{O}$ estudo, portanto, tem por objetivo avaliar a gestão na segurança pública relacionada aos crimes de trânsito envolvendo abuso de 
drogas em uma Unidade de Perícia Científica, no Estado do Pará, visando responder à seguinte questão: os procedimentos adotados na gestão da segurança pública nos delitos de trânsito, envolvendo abuso de drogas, são adequados?

Para alcançar o objetivo geral, o estudo se desenvolveu respondendo aos objetivos específicos a seguir: a) observar a infraestrutura técnica e laboratorial da UPC; b) verificar a adequação das condições de trabalho e dos procedimentos adotados pela gestão da segurança pública nos delitos de trânsito envolvendo abuso de drogas; c) analisar os documentos oficiais disponíveis para o trabalho dos peritos atuantes na UPC.

\section{METODOLOGIA}

Trata-se de um estudo de caso, caracterizado como um estudo profundo a respeito de qualquer assunto em relação a uma unidade social, onde o foco pode ser o indivíduo, o grupo social ou uma organização (LEITE, 2008). Neste estudo, optou-se por analisar uma organização que presta serviço de utilidade pública e de interesse social, com vista ao conhecimento da realidade empírica dos peritos de polícia científica atuantes no município de estudo.

O estudo foi realizado em uma Unidade de Polícia Científica (UPC) no Estado do Pará, região Norte do Brasil, que atende uma área de $1.029 .191 \mathrm{~km}^{2}$ com uma densidade populacional estimada em 147,8 hab/ $\mathrm{km}^{2}$ com clima equatorial e um Índice de Desenvolvimento Humano) (IDH) de 0,698 médio, com base no PNUD (2017). Esta UPC atua em diversas áreas, incluindo os crimes de trânsito. Em sua área de abrangência atende 58 municípios do nordeste do Estado do Pará.

Além de subsidiar questões administrativas, inquéritos policiais e, sobretudo, processos judiciais, são realizadas as perícias técnico-científicas de caráter multidisciplinar como: Documentoscopia Forense, Local de Crime Contra a Vida e o Patrimônio, Exames Veiculares, Engenharia Aplicada, Laboratório Físico-QuímicoBiológico, de DNA, de Toxicologia Forense, Contabilidade Forense, entre outros. 
O estudo foi desenvolvido por meio de observações feitas nos laboratórios de toxicologia da UPC em estudo, a fim de obter informações pertinentes à atuação dos peritos em relação às análises de abuso de drogas; análise documental e pesquisa bibliográfica pertinente. Dentre os documentos analisados foram incluídos modelos de requisição de perícia técnico-científica aplicada pela UPC, laudos periciais de acidentes de trânsito emitidos e documentos oficiais (Leis, Decretos, Portarias), com vista ao embasamento teórico referente ao tema proposto. A pesquisa bibliográfica incluiu fontes primárias (artigos de periódicos, teses e dissertações) e secundárias (registros de informações arquivadas e disponíveis na UPC).

Considerando o que propõe Bardin (2006), a análise de conteúdo neste estudo foi organizada em três fases: pré-análise, exploração do material e tratamento dos resultados (inferência e interpretações).

Na pré-análise, fez-se a organização do material a ser analisado, a fim de sistematizar as ideias. A fase de organização do material consistiu em: a) dos registros da fase de observação; b) documentos oficiais; c) publicações científicas. Na segunda fase, realizou-se a exploração dos documentos sistematizados. Esta é a fase analítica do material coletado. A terceira fase consistiu no tratamento dos resultados, inferências e interpretações, que, segundo Bardin (2006), é o momento da intuição, da análise reflexiva e crítica.

\section{RESULTADOS E DISCUSSÃO}

A formação, a capacitação dos peritos e a infraestrutura laboratorial de uma UPC para o desenvolvimento de perícias técnico-científicas são essenciais para a definição do envolvimento de drogas em acidentes de trânsito. O conhecimento das drogas ilícitas e de seus efeitos facilitam as análises periciais que apoiam as decisões judiciais nos inquéritos envolvendo crimes de trânsito.

Os documentos analisados e os dados de observação local mostraram que a UPC estudada conta com recursos humanos qualificados para a função, embora, parte do quadro técnico estivesse ausente por férias ou licença da unidade, no período do 
estudo. Por outro lado, a infraestrutura laboratorial é limitada, dificultando as análises das principais drogas ilícitas. Neste contexto, questiona-se a limitação da infraestrutura laboratorial da UPC e do reduzido quadro técnico para atender às demandas específicas.

No Brasil, pouco é discutido sobre a gestão das políticas sobre segurança pública, particularmente, das relacionadas aos acidentes de trânsito envolvendo abuso de drogas. O Código de Trânsito Brasileiro ressalta bem os cuidados com o abuso de álcool e a condução de veículos automotores. Apesar de, o CTB estabelecer em linhas gerais penalidades também para indivíduos que estejam envolvidos com drogas em acidentes de trânsito, a lei não deixa clara a forma de abordagem e tipo de drogas que deveriam ser investigadas. Não há definição quanto às considerações sobre o estado de comprometimento que poderia causar o dano, ficando a cargo de cada perito.

Em países desenvolvidos, como na Austrália, o debate sobre o assunto tem sido dominado pela ideia que, particularmente para os crimes que envolvem violência como nos acidentes de trânsito, o nível ou estado de "intoxicação" (entendido como o grau de comprometimento físico ou mental causado pela droga) produzido pelo álcool e outras drogas deve ser considerado como fator agravante que torna o delito mais sério, exigindo punição adicional. Para isso, é necessário que a perícia se baseie no que a lei estabelece. Havendo lacuna na lei, as ações periciais também deixarão lacunas (QUILTER; NCNAMARA; SEEAR, 2016).

Historicamente, o conceito de "intoxicação" na lei criminal brasileira é limitado ao álcool e seus efeitos. Mais recentemente, observa-se a tendência de estender o alcance desse conceito às outras drogas que perturbam o equilíbrio, a cognição e as atividades motoras, alterações encontradas geralmente nos indivíduos envolvidos em acidentes de trânsito sob efeito de drogas ilícitas.

A inclusão generalizada de drogas diferente do álcool nas definições legais é também problemática, particularmente quando a intoxicação é definida como a simples presença de qualquer quantidade de uma droga no corpo de uma pessoa, sem 
referência ao comprometimento ou consequências adversas do consumo e sem o reconhecimento de que drogas têm efeitos diferentes.

Embora a legislação brasileira considere crime, dirigir sob a influência de álcool ou substancia de efeitos análogos (CTB, art. 306, Lei no 9503/1997), e o Conselho Nacional de Trânsito (CONTRAN) através da Resolução 81/1998 estabelece a necessidade de exames para esclarecimento da causa do delito de trânsito, não se identificava espaço maior para o tratamento dos crimes de trânsito associados ao abuso de drogas ilícitas.

Ao longo do período a Legislação sofreu alterações, mas novamente, o foco da alteração foi a embriaguez alcoólica e direção de veículos automotores. Assim, o Art. 165 foi alterado para o seguinte termo "dirigir sob a influência de álcool ou qualquer substância entorpecente ou que determine dependência física ou psíquica" --. O Art.277 define procedimentos diante da recusa a teste de embriaguez pelo condutor, (no caso de recusa do condutor à realização de exames) o agente de trânsito poderia prover provas acerca dos notórios sinais de embriaguez.

A resolução 206/2006 (CONTRAN) disciplina o procedimento de agentes de trânsito diante de tal situação incluindo relatório detalhado assinado pelo agente e por testemunhas.

A Lei № 11.705/2008, Lei Seca, altera o termo na seguinte forma "dirigir sob a influência de álcool ou qualquer outra substância psicoativa", aqui se entende por psicoativa tanto droga lícita como ilícita. E o Art. 277 da mesma lei estabelece tolerância zero para o álcool, determinando que qualquer concentração de álcool no sangue é passível de infração penal (BUSARDO, F. P. et al, 2018).

Em 2012, a Lei № 12.760/2012, nova revisão da Lei Seca, alterou os Art. 165, 262,276, 277 e 306. Esse último estabelecendo as penalidades criminais para quem cometer crimes de trânsito sob a influência de álcool e outras substâncias de efeitos análogos. Nesta nova Lei Seca, o Art. 165 considera infração, qualquer concentração 
de álcool por litro de sangue ou por litro de ar alveolar sujeita o condutor a penalidades previstas na lei.

Observa-se que, ao longo dos anos, a Legislação vem sofrendo alterações direcionadas ao uso do álcool na direção, definindo doses, condutas técnicas e penalidades. Por outro lado, pouco acréscimo foi dado em relação ao uso de drogas psicoativas em crimes de trânsito. A falta de condutas técnicas frente aos delitos de trânsito causados por drogas psicoativas pode deixar lacunas nas perícias médicolegais BACCHIERI et al., 2010).

Investigando o manual de procedimentos médico legal em crimes de trânsito de grandes cidades como Brasília e de São Paulo, verificou-se que no manual do IML do Distrito Federal não há definição e aplicação de normas técnicas para averiguação de drogas que interferem com a condução de veículos (Manual de Rotinas IML/DF, 2014).

No manual do IML/SP (2008), já se observava uma preocupação com os crimes de trânsito envolvendo uso abusivo de drogas. Nesse, há definição de estado de embriaguez (quadro sindrômico que pode ser causado por álcool etílico, drogas psicoativas, doenças neurológicas quer isolados ou associados), estabelece alguns procedimentos para realização de exame toxicológico para o álcool e outras drogas. O exame toxicológico como parte do exame de verificação de embriaguez, busca encontrar, através da análise de fluidos biológicos principalmente, no sangue e urina, a substância ou substâncias causadoras do estado de embriaguez e respectiva concentração.

No corrente estudo, os documentos utilizados pelos peritos em acidentes de trânsito não auxiliam em tomadas de decisão quanto a procedimentos na execução de perícias técnicas para elaboração do laudo pericial. Por outro lado, não existe na UPC um protocolo de condutas técnicas nos casos de acidentes envolvendo abuso de drogas. Os procedimentos realizados são aqueles requisitados pelo delegado ou outra autoridade requisitante, que geralmente, não auxilia a atuação do perito, que realiza a perícia de acordo com o seu entendimento. E, como não requisita a pesquisa de 
drogas ilícitas, na maioria das vezes é investigado apenas o envolvimento do álcool. Portanto, não existe um protocolo de conduta diante de casos de acidentes de trânsito. A existência de protocolo de procedimentos facilitaria a atuação do perito bem como contribuiria para a condução do laudo pericial que vai subsidiar a análise judicial.

Assim, destaca-se a importância da gestão no fortalecimento da estrutura laboratorial e a responsabilidade por um instrumento legal que possa auxiliar os peritos na melhor condução de suas atividades em acidentes de trânsito com envolvimento de drogas psicoativas. Percebe-se, portanto, a necessidade de normas complementares, de protocolo de procedimento para realização das perícias definindo melhor, o envolvimento das drogas nos crimes de trânsito, como tem sido considerado para o uso do álcool.

O estabelecimento de normas e padronizações que identifique as drogas envolvidas e os danos por elas causados em crimes de trânsito atenderá ao preenchimento desta lacuna na legislação que dará maior consistência aos laudos periciais e às decisões judiciais.

\section{CONCLUSÃO}

A Gestão na segurança pública relacionado aos crimes de trânsito envolvendo abuso de drogas na UPC estudada conta com um quadro técnico com qualificação pertinente, apesar do número reduzido de peritos para o atendimento das demandas; garante limitada condição de trabalho para a realização das perícias, em relação a infraestrutura laboratorial e ausência de protocolo de procedimentos; conta com instrumentos legais que não atendem as demandas específicas (acidentes envolvendo o uso de drogas).

Portanto, os procedimentos adotados na gestão da segurança pública nos delitos de trânsito, envolvendo abuso de drogas são limitados. O estudo mostra que há limitações para a realização das perícias técnico-científicas que dão suporte necessário às decisões judiciais frente aos crimes de trânsito envolvendo abuso de 
drogas, e que há necessidade de melhorias no planejamento e na avaliação da gestão na segurança pública referente aos crimes de trânsito.

\section{REFERÊNCIA}

ALVAREZ, F. J.; FIERRO, I.; DEL RIO, M. C. Cannabis and driving: results from a general population survey. Forensic Science International, v.170, n.2, (3), p.111116, 2007.

BACCHIERI, G. et al. Traffic accidents in Brazil from 1998 to 2010: many changes and few effects. Revista de Saúde Pública, v.45, n.5, p.940-963, 2010.

BARDIN, L. Análise de conteúdo. Lisboa, Portugal: Ed. 70, 2006.

BRASIL. Decreto-Lei no 11.705/2008 de 19 de junho. Altera a Lei No 9.503, de 23 de setembro de 1997. Código de Trânsito Brasileiro (CTB). 2008.

. Decreto-lei o 12.760, de 20 de dezembro de 2012. Altera o art. 306 do código de trânsito brasileiro (CTB). Disponível em< http://jus.com.br/revista/texto/23321/lei no-12-760/2012 a nova lei seca, 2012 a.

. Decreto-lei o 12.760, de 20 de dezembro de 2012. Altera o art. 306 do código de trânsito brasileiro (CTB). Disponível em< http:/jus.com.br/revista/texto/23321/lei no-12-760/2012 a nova lei seca, 2012 a.

. Decreto-Lei no 9.503/1997 de 24 setembro. Código de Trânsito Brasileiro (CTB)., 1997

. Ministério da Saúde. DATASUS. 2014. Mortos em acidentes de trânsito. http://www.vias-

seguras.com/os_acidentes/estatisticas/estatisticas_nacionais/estatisticas _do_ministerio_da_saude.

Ministério do Planejamento, Desenvolvimento e Gestão. Acidentes de trânsito nas rodovias federais brasileiras. Caracterização, tendências e custos 
para a sociedade. Relatório de Pesquisa. Brasília: Instituto de Pesquisa Econômica Aplicada, recuperado a 18 de outubro de 2016, de http://www.ipea.gov.br.

. Resolução n² 206/2006 de 20 de outubro. Conselho Nacional de Trânsito (CONTRAN), Brasília-DF. BRASIL.

BRASÍLIA- DF. INSTITUTO DE MEDICINA LEGAL Leonídio Ribeiro. Manual de Rotinas, Brasília -DF,2014, p.64-88. Disponível em: https://www.tjdft.jus.br/institucional/corregedoria/MANUALDEROTINASIML.pdf

BUSARDO, F. P. et al. Correlation between Blood and Oral Fluid Psychoactive Drug Concentrations and Cognitive Impairment in Driving under the Influence of Drugs. Current Neuropharmacology, v.16, p.84-96, 2018.

CAMPOS, V. R.; SALGADO, R..; ROCHA, M. C.; DUAILIBE, S.; LARANJEIRA, R. Prevalência do beber e dirigir em Belo Horizonte, Minas Gerais, Brasil. Cad. Saúde Pública, Rio de Janeiro, v. 24, n.4, p.829-834, 2008.

COSTA, N. et al. Prevalence of etanol and illicit drugs in road traffic acidentes in the Centre of Portugal: An eighteen-year update. Forensic Scence International, v.216, n. 1(3), p.37-43, march, 2012.

HIGSON, R.; WINTER, M. Epidemiology and consequence of drinking and driving. Alcohol Res. Health, v.27, n.1, p.63-68, 2003.

KARJALAINEN, K. K. et al. Poly-drug findings in drugged driving cases during 19772007. Journal of Substance Use, v. 15, n.2, p.143-156, 2010.

LEYTON, V. et al. Trends in the use of psychoactive substances by truck drivers in São Paulo State, Brazil: A time-series cross sectional roadside survey (2009-2016). Traffic Injury Prevention, v. 20, n.2, p. 122-127, 2019.

MALTA, D. C. et al. Consumo de bebidas alcoólicas e direção de veículos nas capitais brasileiras e no Distrito Federal, segundo dois inquéritos nacionais de saúde. Rev Bras Epidemiol., v. 18, n.2, p.214-223, 2015. 
MURA, P. et al. Use of drugs of abuse in less than 30-year-old drivers killed in a road crash in France: A spectacular increase for cannabis, cocaine and, amphetamines. Forensic Science International, v.160, n.23, p.168-172, july, 2006.

NUNES, O. P. Mortes violentas relacionadas ao consumo de drogas Psicoativas na região metropolitana de Belém: estudo Prospectivo no período de janeiro a dezembro de 2011. Belém-Pará, 2012. Originalmente apresentada como dissertação de Mestrado do Programa de Pós-graduação Saúde, Sociedade e Endemias da Amazônia. Universidade Federal do Pará, 2012.

PARÁ. Secretaria de Estado de Segurança Pública. Departamento de Trânsito (DETRAN-PA). Relatório Estatístico de Trânsito 2007 a 2009, Belém - Pará, 2010

PNUD - PROGRAMA DAS NAÇÕES UNIDAS PARA O DESENVOLVIMENTO, IDH, 2017.

QUILTER, J.; MCNAMARA, L. J.; SEEAR, K. Criminal law and the effects of alcohol and other drugs: a national study of the significance of "intoxication". Australian Legislation, University of New South Wales Law Journal, 913-949, 2016,

SÃO PAULO (Estado). Polícia Civil. Manual prático de apuração do crime de embriaguez ao volante. (Coord. Ricardo Cardozo de Mello Tucunduva). São Paulo: Academia de Polícia “Dr. Coriolano Nogueira Cobra”, 2013.

SCHERER, J. N. et al. Predictive factors associated with driving under the influence among Brazilian drug-using drivers. Accident Analysis and Prevention, v.123, p. 256-262, 2019.

SIMONSEN, K. W.; LINNET, K.; RASMUSSEN, O. S. Driving under the influence of alcohol and drugs in the eastern part of Denmark in 2015 and 2016: Abuse patterns and trends. Traffic Injury Prevention, v.19, n.5, p. 468-475, 2018. 
SOUZA, M.; MUNHÕZ, D. R. A influência do álcool e outras drogas na condução de veículos automotores e a utilização do exame clínico como meio de prova nas infrações e crimes de trânsito. Saúde, Ética \& Justiça, v. 5, n.7, p. 24-31, 2002.

VEISTEN, K. et al. Is law enforcement of drug - impaired driving cost-efficient? An explorative study of a methodology for cost-benefit analysis. The International Journal on drug policy, v.24, n.2, p.122-134,2013.

WORLD HEALTH ORGANIZATION (WHO, 2009). Global status report on road safety: time for action., Geneva, Switzerland. Recuperado a 01 outubro 2016, de http:/who.int/violence_injury_whqlibdoc.who.int/publications/2009/9789241563840.

Enviado: Dezembro, 2019.

Aprovado: Dezembro, 2019. 